\title{
A IMPORTÂNCIA DAS CARACTERÍSTICAS PESSOAIS DO AUDITOR DE SISTEMA DE GESTÃO
}

\section{THE IMPORTANCE OF THE PERSONAL'S SKILLS OF THE MANAGEMENT SYSTEM AUDITOR}

\author{
Aldoney Freire Costa \\ Pesquisador-Tecnologista \\ Instituto Nacional de Metrologia, Normalização e Qualidade Industrial - INMETRO \\ Coordenação Geral de Credenciamento \\ Rua Santa Alexandrina, 416 / $7^{\circ}$ andar - Rio Comprido - Rio de Janeiro - CEP 20261-232 \\ Telefone: (021) 2563-5530 - afcosta@inmetro.gov.br \\ José Rodrigues de Farias Filho, D.Sc. \\ Professor Adjunto \\ Escola de Engenharia do CTC/UFF \\ Departamento de Engenharia de Produção \\ Rua Passo da Pátria, 156 - sala 240 - Prédio Novo da Escola de Engenharia - São Domingos \\ - Niterói - RJ - CEP 24.210-240 \\ Telefone: 2629-5396 - rodrigues@latec.uff.br
}

RESUMO

A alta competitividade e a rapidez de mudanças nos mercados do mundo globalizados têm obrigado as organizações a utilizarem novas alternativas de gestão mais flexíveis e adaptadas à nova realidade, sendo a auditoria de sistema de gestão uma ferramenta de avaliação do gerenciamento de seus processos, que permite aos administradores avaliar seu rumo e desempenho.

O artigo dá uma visão geral da relevância desta atividade na avaliação de um processo de gestão das organizações, demonstrando a importância das características pessoais de um auditor, quando no exercício das atividades de auditoria de sistemas de gestão, e como estas características devem ser levadas em consideração no momento de alocar recursos humanos para este tipo de atividade.

Palavras-chave: Auditor; Atributos pessoais; Sistemas de Gestão. 


\begin{abstract}
The high competitiveness and the faster changes in the world markets have debtor the organizations to use new alternatives of management, more flexible and adapted to the new reality, being the auditorship of management system a tool of evaluation of the management of its processes, that allows the administrators to evaluate its route and performance. The article gives to a general vision of the relevance of this activity in the evaluation of a process of management of the organizations, demonstrating the importance the personal's characteristics of an auditor, when in the exercise of the activities of auditorship of management systems, and as these characteristics must be taken in consideration at the moment to place human resources for this type of activity.
\end{abstract}

Key-words: Auditor; personal’s skills; management systems.

\title{
1. INTRODUÇÃO
}

A rapidez de mudanças no mercado globalizado têm obrigado as organizações a utilizarem novas alternativas de gestão adaptadas à nova realidade, sendo a auditoria de sistema de gestão uma ferramenta importante de avaliação do gerenciamento de seus processos, que permite aos administradores avaliar seu rumo e desempenho.

As auditorias de sistemas de gestão fornecem evidências objetivas para a gerência da organização auditada sobre a adequação, conformidade às exigências e eficácia dos vários elementos componentes do sistema de gestão.

O sucesso de uma auditoria está fundamentalmente ligado à qualificação do auditor, que são indivíduos que possuem formação e atributos bem específicos para o desempenho deste tipo de atividade.

Os auditores devem ter atributos profissionais específicos, que são conhecimentos relacionados ao tipo de auditoria a ser realizado e o processo específico da organização. Mas além dos atributos profissionais, a competência do auditor de sistema de gestão deve ser complementada com algumas características pessoais que permitirão ao auditor realizar sua atividade com eficácia. Esta eficácia, em grande parte, depende do relacionamento interpessoal entre o auditor e o auditado.

$\mathrm{Na}$ escolha de indivíduos para atuarem em auditorias de sistema de gestão, devem avaliadas as reais qualificações necessárias a um auditor de sistema de gestão, levando-se em consideração seus atributos pessoais, além das qualificações profissionais inerentes ao tipo de auditoria a ser realizado. 


\section{METODOLOGIA}

O objetivo geral desta pesquisa é o de contribuir para uma visão das reais qualificações que devem ser necessárias a um auditor de sistema de gestão, levando-se em consideração seus atributos pessoais.

Este estudo classifica-se como de pesquisa exploratória e descritiva, pois a pesquisa exploratória se presta a esclarecer conceitos e idéias em função de formulação de problemas mais precisos com o objetivo de proporcionar uma visão geral acerca das atribuições pessoais dos auditores de sistemas de gestão. A pesquisa exploratória também ajuda os pesquisadores a aumentar o seu grau de conhecimento sobre o tema pesquisado. O trabalho também se presta a descrever características do processo de auditoria de sistema de gestão, bem como a estabelecer relações entre as atividades desenvolvidas e as características pessoais dos auditores. Do ponto de vista da abordagem do problema, é uma pesquisa qualitativa. O método dedutivo empregado nesta pesquisa objetiva confirmar as suposições formuladas, a partir da análise de informações disponíveis nos dispositivos normativos e na literatura.

No delineamento do artigo, foram utilizados o referencial teórico, a análise documental e a coleta de informações, tomando-se como base o tema de auditoria em sistemas de gestão e características pessoais importantes para esta atividade.

$\mathrm{Na}$ confecção deste artigo, fizemos uma pesquisa de textos, artigos ou livros, que demonstram quais as características pessoais de auditores que são de fundamental importância no desempenho de suas funções, além de avaliar como a utilização destas características contribui com a eficácia de sua atividade

\section{DESENVOLVIMENTO}

\subsection{Auditoria de Sistemas de Gestão}

Devido, principalmente, à evolução natural do mundo capitalista, a transformação de empresas familiares em organizações administradas por terceiros, ao processo de globalização de negócios, surgiu a auditoria de sistemas de gestão, que é a atividade de exame e avaliação de procedimentos, processos, sistemas, registros e documentos, com o objetivo de aferir o cumprimento dos planos, metas, objetivos e políticas de uma organização. 
Segundo W. Holmes, no seu livro Auditing Principles and Procedures, define auditoria como o exame das demonstrações e registros administrativos. O auditor verifica a exatidão, integridade e autenticidade de tais demonstrações, registros e documentos.

A definição contida na norma NBR ISO 19011:2002 (Diretrizes para auditorias de Sistema de Gestão da Qualidade e Sistema de Gestão Ambiental), auditoria é: "Processo sistemático, documentado e independente para obter evidências de auditoria e avaliá-las objetivamente para determinar a extensão na qual os critérios da auditoria são atendidos".

Esta definição mostra que as auditorias são executadas de forma planejada e com freqüência definida, conforme as necessidades da organização. O objetivo é de buscar fatos reais (evidência de auditoria) que devem ser avaliados conforme os requisitos do sistema de gestão e norma de referência (critérios de auditoria) visando à eficácia do sistema.

A auditoria de sistemas de gestão é uma ferramenta gerencial utilizada para avaliar, confirmar ou verificar as atividades relacionadas ao gerenciamento do sistema de gestão. A condução de uma auditoria com este propósito, constitui um processo que agrega valor à empresa, pois ajuda a evitar ou antever problemas na gestão da organização, devido ao surgimento dos problemas ocorrerem pela ineficiência ou inadequação do sistema de gestão.

Para algumas pessoas, as auditorias de sistemas de gestão têm uma conotação negativa, pois é encarado como um processo de fiscalização e para estabelecer culpas. Este conceito é errôneo, pois, fundamentalmente, uma auditoria de sistema de gestão tem por finalidade de identificar as oportunidades de melhoria no processo, a busca da satisfação do cliente interno e externo, ser uma ferramenta de avaliação do desempenho do sistema de gestão da organização. Para isto devemos ter consciência que os auditores não avaliam as pessoas e sim os processos, que são buscadas as conformidades no processo, e que as não conformidades são uma conseqüência do não cumprimento de algum procedimento ou norma.

A auditoria em questão, é uma ferramenta de grande importância para o gerenciamento do sistema de gestão de qualquer empresa, uma vez que fornece os subsídios para uma avaliação e aperfeiçoamento da eficácia do processo de gestão.

As auditorias de sistemas de gestão fornecem evidências objetivas para a gerência da organização auditada sobre a adequação, conformidade às exigências e eficácia dos vários elementos componentes do sistema de gestão.

\subsection{Auditores}


Os atributos a serem buscados num auditor de sistemas de gestão podem ser divididos em duas categorias:

a. Atributos profissionais

b. Atributos pessoais

As duas categorias acima se completam, pois os atributos profissionais são os conhecimentos relativos ao desempenho da atividade de auditoria, aliado à experiência profissional no processo a ser auditado, e os atributos pessoais são habilidades e aptidões que dão suporte ao auditor para o perfeito desempenho de sua função. A seguir faremos uma breve discussão sobre estas duas categorias de atributos.

\subsubsection{Atributos profissionais}

Um auditor de sistema de gestão competente deve ter uma ampla base de conhecimentos relativos à área específica da gestão da organização auditada, deve estar a par das últimas inovações dos processos de gestão, estar atualizado nas novidades da informática, conhecer novas tecnologias de produtos, uma visão econômica capaz de identificar ameaças ao seu cliente.

$\mathrm{O}$ auditor, no exercício das atividades de auditoria, deve possuir um conjunto de conhecimentos técnicos, experiência e capacidade para as tarefas que executa; conhecimentos de disciplinas específicas para o adequado cumprimento do objetivo da auditoria.

A competência profissional é adquirida pela aplicação prática dos conhecimentos técnicos. O somatório de conhecimento e experiências obtidas entre várias situações contribuem para o desenvolvimento do julgamento profissional, possibilitando-o discernir entre situações gerais e particulares.

O auditor deve manter sua qualificação técnica, atualizando-se quanto ao avanço de normas, procedimentos e técnicas aplicáveis à auditoria. Existe a necessidade do auditor ter um programa de educação continuada, atualizando-se e ampliando seus conhecimentos técnicos, além de realizar auditorias periodicamente, de modo a não perder seu senso de percepção, estando assim capacitado a realizar serviços de excelente qualidade e poder satisfazer plenamente os seus clientes. 


\subsubsection{Atributos pessoais}

Os atributos pessoais necessários a um auditor são baseados no senso de feedback que ele deve utilizar com a finalidade de passar e obter confiança em sua atividade, pois as conclusões dos auditores são baseadas em informações documentais e pessoais, informações estas que só podem ser obtidas se houver a confiança do auditado, de que as informações serão utilizadas para agregar valor à sua atividade.

Um auditor de sistemas de gestão não deve ser aquela pessoa desagradável que vinha somente fiscalizar as atividades realizadas e procurar falhas. Esta postura causa retração, temor e reatividade por parte do auditado. Contudo, a auditoria de sistemas de gestão precisa destacar os pontos fortes do sistema, ao mesmo tempo em que identifica as deficiências.

Um auditor, no exercício da atividade de auditoria, deve manter atitude que garanta a eficácia do processo de auditoria, alguns deles são citados abaixo;

- Independência que assegure a imparcialidade de seu julgamento;

- Acatar as normas de ética profissional;

- Ter bom senso em seus atos e recomendações;

- Cumprimento das normas gerais de auditoria;

- Ser prudente quando estabelecer uma adequada extensão dos seus exames;

- Atuar com habilidade, precaução e esmero de modo a reduzir ao mínimo possível a margem de erro;

- Ter um tratamento pessoal com as pessoas auditadas, de forma a inspirar um intercâmbio livre de fatos e idéias;

- Manter a calma e frieza durante todas as fases da auditoria;

- Exibir um ar de confiança, mas não excessiva, nem arrogante;

- Demonstrar honestidade e objetividade ao relatar as constatações de uma auditoria;

- Trabalhar de maneira planejada e sistemática, sem mostrar tendências autoritárias.

- Ser um observador atento de detalhes das áreas e atividades associadas.

\subsection{O Relacionamento pessoal}

Um dos aspectos mais importantes para o auditor se relacionar bem com o auditado, é a empatia, isto é, o auditor tentar colocar-se no lugar do auditado. Esse comportamento permitirá o auditor avaliar se as recomendações feitas, são viáveis. 


\subsection{Fatores que contribuem para a eficácia e a qualidade do feedback}

Existem alguns ações que contribuem para a eficácia e a qualidade do feedback, dentre elas destacamos os seguintes:

- Deve ficar bem claro que ao dar o feedback a intenção é contribuir para o melhorar e desenvolver o outro;

- Expressar realmente o que se pensa e sente;

- É preciso dizer a verdade mas com sensibilidade e habilidade, de forma a não estimular e provocar atitudes defensivas;

- Tentar ganhar a confiança da outra parte de modo a que ela se desarme e se predisponha a ouvir;

- Reconhecer os pontos fortes/positivos é fundamental do ponto de vista psicológico, é o reconhecimento do que a pessoa tem de bom que dá a ela a força e a segurança para ouvir sobre o que tem a melhorar;

- Falar de forma clara, evitando obscuridades. Dar exemplos, ajudando a parte interessada a aprender melhor;

- Saber ir aos pontos mais importante e prioritários, evitando prolixidade e detalhes sem importância;

- Ter o senso exato do que se afirma, evitando julgamentos radicais e generalizados;

- Sempre que necessário, tomar a iniciativa para receber ou dar feedback. Não esperar que os outros venham primeiro. Demostrar que ele será sempre bem recebido.

\section{DISCUSSÃO E CONCLUSÃO}

$\mathrm{O}$ artigo teve a intenção de contribuir com informações que demonstram como é importante que os auditores de sistemas de gestão sejam selecionados cuidadosamente, levando-se em consideração não só seus atributos profissionais, que obviamente não podem ser esquecidos, mas também os atributos pessoais, que são tão importantes quantos os primeiros, pois têm impacto diretamente na eficácia de uma auditoria, pois ela está fortemente associada aos relacionamentos pessoais entre o auditor e a equipe auditada. O pessoal da organização auditada precisa ter confiança na objetividade, competência, conhecimento técnico e habilidade do auditor ao fazer avaliações válidas. 
Ao se selecionar uma pessoa para exercer a atividade de auditor de sistema de gestão, deve-se ter a visão do conjunto de atributos descritos neste artigo, principalmente indivíduos que tenham a capacidade de trabalhar com pessoas. Um tipo de indivíduo que deve ser evitado a qualquer custo, é aquele que encara a auditoria como uma fonte de poder sobre os demais membros da organização que está sendo auditada.

As características pessoais essenciais de um auditor são, possuir boa capacidade de comunicação e relacionamento interpessoal com o auditado, de resolver situações de conflito, além de ser responsável e profissional.

\section{REFERÊNCIAS}

MILLS, Charles A. A Auditoria da Qualidade - Uma ferramenta para avaliação constante e sistemática da manutenção da Qualidade. Makron Books, 1994

ARAÚJO, Inaldo da Paixão Santos. Introdução à auditoria operacional. Rio de Janeiro: Editora FGV, 2001.

HOlMES, Arthur W. Auditing principles and Procedures. Chicago: Business Publications, Inc., 1939

ASSOCIAÇÃO BRASILEIRA DE NORMAS TÉCNICAS. NBR ISO 19011:2002 Diretrizes para Auditorias de Sistema de Gestão da Qualidade e/ou Ambiental.. Rio de Janeiro: ABNT, 2002.

ASSOCIAÇÃO BRASILEIRA DE NORMAS TÉCNICAS. NBR ISO 9001:2000 Sistemas de Gestão da Qualidade - Requisitos. Rio de Janeiro: ABNT, 2000.

ASSOCIAÇÃO BRASILEIRA DE NORMAS TÉCNICAS. NBR ISO 9000: Sistemas de gestão da qualidade - Fundamentos e vocabulário. Rio de Janeiro: ABNT, 2002.

Artigo recebido em 16/07/2006 e aceito para publicação em 21/08/2007. 